\title{
O USO DA FOTOGRAFIA NA FORMAÇÃO EM SERVIÇO DE EDUCADORES DE CRECHE
}

\author{
Ana Rosa Costa Picanço Moreira ${ }^{1}$
}

\section{INTRODUÇÃO}

Este trabalho é parte de um estudo maior, cujo título é "Ambientes da infância e a formação do educador: arranjo espacial na creche", e discute sobre o uso da fotografia para a problematização e reflexão da organização espacial dos ambientes da creche, no contexto de formação em serviço das educadoras que trabalham com crianças de quatro a vinte e quatro meses de idade.

No âmbito da educação, de acordo com Oliveira e Tambara (2010), a fotografia tem sido principalmente empregada na investigação do cotidiano da escola, arquitetura escolar e memória de professores e alunos.

O filósofo Walter Benjamin (2012, p. 101) advoga que a fotografia torna acessível aquilo que nossos olhos não conseguem perceber: "a fotografia revela esse inconsciente ótico", pois interrompe o olhar viciado ao propiciar outros ângulos de visão. Para Kossoy (2001, p. 156), a fotografia é "[...] a paralisação súbita do incontestável avanço dos ponteiros do relógio: é, pois, o documento que retém a imagem fugidia de um instante de vida que flui ininterruptamente."

A fotografia possibilita a percepção de uma realidade invisibilizada por meio do olhar do fotógrafo. O fotógrafo, portanto, faz parte da imagem. Sua presença pode ser notada pela escolha estética, técnica ou ideológica na composição da imagem (SÔNEGO, 2010). Groisman (2006) afirma que o ato de fotografar e a fotografia promovem experiências para além do que revelam as imagens produzidas pela câmera. A tomada da foto está imbricada num ciclo técnico, estético, político e relacional. Gusmão e Jobim e Souza (2008, p. 25) complementam essa ideia afirmando que:

As fotos revelam escolhas diante de um universo infinito de imagens possíveis. E é aí que técnica e subjetividade se entrelaçam. A fotografia não é um registro mecânico da realidade. Muito mais que isso, a foto traz grafada a subjetividade do fotógrafo.

\footnotetext{
${ }^{1}$ Universidade Federal de Juiz de Fora. ana.moreira@ufjf.edu.br
} 
Assim, as significações das imagens são produzidas na relação entre sujeito e o que é visível e invisível nas imagens. Perceber algo é produzir sentido sobre esse algo a partir de uma relação concreta. É nessa direção que pretendemos abordar a fotografia: não como técnica capaz de capturar a realidade, mas, sobretudo, como meio de produção de realidades.

Sendo a fotografia um modo de produção de significações, interessa-nos pensá-la também como recurso pedagógico na formação de educadores de creche servindo de mote para repensar práticas educativas naturalizadas e provocar transformações a partir da reflexão crítica e coletiva.

\section{A FOTOGRAFIA E A PRODUÇÃO DE REALIDADES}

Com o advento das tecnologias de comunicação visual na modernidade, a fotografia possibilitou a emergência do mundo imagem (SONTAG, 2004), isto é, o mundo traduzido em imagens. Como diz Benjamin (2012), a fotografia permitiu gerar imagens do mundo de modo vivo e verídico como a natureza. O mundo moderno "[...] prefere a imagem à coisa, a cópia ao original, a representação à realidade, a aparência ao ser [...]" (SONTAG, 2004, p. 169), substituindo o mundo real pelo mundo imagem. A verdade deixa de ser $o$ fato em si para ser a imagem que $O$ representa. A imagem é a interpretação do mundo. A valorização da imagem em detrimento ao fato em si faz com que a nossa percepção e concepção de mundo seja fortemente de cunho imagético.

Compartilhamos com Lisboa e Pires (2010) a ideia de que a fotografia expressa modos de interpretação do mundo com base em aspectos subjetivos e sócio-históricos das pessoas que a produzem. Nessa direção, Kossoy (2001) adverte que o processo de fotografar encontra-se circunscrito ao momento histórico, condicionando a atuação do fotógrafo enquanto filtro cultural.

Lopes (2004) também chama nossa atenção para o quanto que a fotografia propicia a flexibilização do olhar na medida em que permite a relação entre imagem e palavra. Para a autora, a foto convida a múltiplas interpretações que são o resultado do diálogo entre o fotógrafo, a fotografia e o observador. Acrescenta Lima (1988) que é na interpretação da foto que está o seu caráter polissêmico. A fotografia, portanto, é prenhe de intenções e significados - "[...] não fotografamos 
apenas com nossa máquina, mas sim com toda nossa cultura e nossa visão de mundo (ideológica ou utópica) (LISBOA; PIRES, 2010, p. 78). Nesse sentido, a fotografia não é simplesmente uma técnica; ela constitui-se numa narrativa potente de expressão de ideias e posicionamentos políticos e ideológicos.

Para Justo e Vasconcelos (2009) a fotografia tem o propósito de dar visibilidade ao recorte da realidade que o autor selecionou para capturar, construindo sentido para aquilo que até então era despercebido. Portanto, o sentido não está contido na imagem em si, mas, ao contrário, ele só pode ser concebido na relação entre sujeito e imagem.

Sob o signo da perspectiva histórico-cultural, pautada no pensamento de Lev Vigotski (1984), entendemos que a fotografia constitui-se num sistema simbólico o qual cria formas de interação do homem com sua realidade e de produção de sentidos sobre essa realidade. Nessa perspectiva, a fotografia se constitui como elemento mediador da relação homem-realidade a qual transforma a realidade e o próprio homem. Ou seja, ela é um meio de intervenção na realidade; de significar a realidade.

\section{AMBIENTES DA CRECHE E DESENVOLVIMENTO INFANTIL}

A discussão sobre as relações estabelecidas entre as crianças/os bebês e os espaços na educação infantil, sobretudo na creche, é recente e são poucas as pesquisas que relacionam essa questão com a formação em serviço. No entanto, diferentes áreas do conhecimento, como a Psicologia, a Arquitetura, a Geografia e a Educação, sob diferentes aportes teórico-metodológicos têm se dedicado ao estudo das relações entre espaço físico e desenvolvimento infantil na creche (LEGENDRE, 1983, 1989, 1999; CAMPO-DE-CARVALHO, 1990; MOREIRA, 1992; MENEGHINI, 2000; BOMFIM, 2002, 2006).

Partimos do pressuposto de que a relação entre ambiente e pessoa não ocorre diretamente, mas, ao contrário, ela é mediada por significados e sentidos construídos histórica e socialmente. Nesse sentido, adotamos um olhar históricocultural para o espaço pautado nas ideias de Lev Vigotski, que considera o meio (espaço/ambiente) um elemento fortemente relacionado ao desenvolvimento infantil na medida em que a criança e o seu ambiente formam uma unidade. Esse teórico destaca a necessidade de concebermos o espaço numa dimensão dialética na qual 
espaço e pessoa não se oponham, mas, sobretudo, sejam entendidos como dois elementos interdependentes, onde um não pode existir sem o outro.

Vigotski (1935/2010) explica que o meio (espaço/ambiente/lugar) nunca é estático, se modificando em cada momento da vida da criança. Para ela, o ambiente é o seu mundo, um contexto de interações que vai ganhando novos sentidos conforme suas experiências cotidianas. Portanto,

[...] no começo também se trata de um mundo muito pequeno, o mundo do quarto, o mundo do parque mais próximo, da rua. Com os passeios, seu mundo aumenta e, cada vez mais, novas relações entre a criança e as pessoas que a circundam tornam-se possíveis. [...] Cada idade possui seu próprio meio, organizado para a criança de tal maneira que o meio, no sentido puramente exterior dessa palavra, se modifica para a criança a cada mudança de idade (VYGOTSKY, 1935/2010, p.683). (grifo nosso)

O ambiente é o mundo na relação com a criança, um contexto de interações que vai ganhando novos sentidos conforme as vivências da criança, as quais se constituem nas bases para a compreensão do mundo e de si própria. Nesse sentido, o ambiente e a criança formam uma unidade. Vigotski denomina Perejivanie/vivência à relação entre a criança e o ambiente (PRESTES, 2012). Conforme acentua Prestes (2012, p.129-130), “(...) para compreender e estudar o desenvolvimento humano é preciso conhecer o ambiente na sua relação com as especificidades de cada indivíduo". O ambiente só é algo a partir da interpretação de alguém. Sendo a vivência a condição própria e singular de cada contexto de ser e estar do sujeito no mundo, é ela que possibilita a emergência de significações [sempre particulares] para os significados [sociais] do meio.

\section{PERCURSO METODOLÓGICO}

Partindo desse referencial teórico-conceitual, realizamos uma pesquisaintervenção numa creche pública do município de Juiz de Fora, Minas Gerais, que utilizou a fotografia como estratégia de produção de dados e recurso pedagógico na formação em serviço de educadores.

O estudo é de cunho interventivo e dialógico, isto é, comprometida com os processos de mudança e transformação. Assim como Freitas (2010, p. 19), utilizamos o sentido da palavra intervenção na perspectiva histórico-cultural: "[...] mudança no processo, transformação, re-significação dos pesquisados e do 
pesquisador, ação mediada, compreensão ativa.", e privilegiamos, por conseguinte, a dimensão processual da pesquisa, com destaque para a relação dialógica entre os participantes, procurando ter uma escuta sensível e potente para a reflexão e transformação das ações.

A pesquisa empírica ocorreu durante os meses de abril e maio de 2013, e teve a participação de seis educadoras que trabalhavam nos berçários 1 e 2 (agrupamentos de crianças de 4 a 24 meses de idade). Buscamos problematizar a organização espacial dos ambientes de referência mediante a discussão de fotos produzidas pelas próprias educadoras.

Foram planejados dois momentos interdependentes: (1) produção de imagens pelas educadoras; e (2) análise e discussão dessas imagens e da linguagem fotográfica como recurso pedagógico.

No primeiro momento, denominado oficina de autoria de imagens, as educadoras foram convidadas a produzir dez fotos das salas de atividades. No segundo momento, chamado sessão reflexiva, as educadoras foram desafiadas a analisarem as imagens produzidas. As sessões reflexivas constituem-se em espaços de problematização e discussão coletiva visando a desnaturalização do que é habitual ou familiar. Segundo Szundy (2005, p.90), as sessões reflexivas são entendidas como "[...] contextos de criação de oportunidades de construção de significados sobre a prática docente em colaboração com um pesquisador externo e se caracterizam como sessões de discussão".

As oficinas tiveram o intuito de desenvolver a produção/construção de um objeto que materializasse a temática da sessão reflexiva a ela vinculada. Para tanto, as educadoras foram incentivadas a produzir dez fotos dos ambientes de referência (salas de atividades), utilizando a câmera digital da creche, ao longo de uma semana. De acordo de Santaella (1998), o ato fotográfico é a expressão visual de um autor, com significados, muitas vezes, desconhecidos até para ele mesmo. $\mathrm{O}$ resultado dessa etapa foi a produção de imagens dos ambientes nos quais as crianças apareciam interagindo com seus pares em brincadeiras diversas.

Durante a sessão reflexiva, que teve duração de aproximadamente noventa minutos, as educadoras foram solicitadas a apresentarem as fotos produzidas e a descrevê-las criando um título (legenda) para cada uma e justificando-os. Em seguida, pedimos que elas selecionassem quatro fotos que 
representassem esses ambientes e que comentassem sobre as suas escolhas. De acordo com Sônego (2010, p. 114),

Os diferentes autores que adotaram a fotografia como instrumento ou objeto de pesquisa, embora realizem trajetórias diferentes em suas construções metodológicas, apontam a necessidade de desconstrução do aparente [...] bem como o contexto em que foram realizadas e a utilização da linguagem verbal para o preenchimento das brechas e silêncios deixados pela imagem.

Sobre o papel do pesquisador, compartilhamos com Justo e Vasconcelos (2009) que ele atua como um disparador do processo de significações que emergem no grupo alimentando a participação de todos.

\section{RESULTADOS}

Em meio a negociações de imagem e temáticas que emergiram da leitura das imagens, as educadoras nomearam e selecionaram as fotos. A seguir, apresentamos nos quadros 1 e 2 os títulos das fotos produzidas pelas educadoras dos berçários 1 e 2, respectivamente, durante a sessão reflexiva. Cabe ressaltar que as educadoras do Berçário 1 só conseguiram produzir nove fotos.

Quadro 1: Títulos das fotos produzidas pelas educadoras do Berçário 1

\begin{tabular}{|l|l|l|}
\hline \multicolumn{1}{|c|}{ Foto } & \multicolumn{1}{|c|}{ Título } & \multicolumn{1}{c|}{ Descrição } \\
\hline 1 & Me espera aí, Henrique! & $\begin{array}{l}\text { Duas crianças andando sobre uma } \\
\text { "ponte", o menino na frente da menina }\end{array}$ \\
\hline 2 & Amigos para sempre & Duas crianças se olhando \\
\hline 3 & Brincadeiras de criança & Duas crianças brincando \\
\hline 4 & É só felicidade! & $\begin{array}{l}\text { Criança brincando com uma rodinha de } \\
\text { plástico sobre o tatame }\end{array}$ \\
\hline 5 & Hora do banho & Criança tomando banho na banheira \\
\hline 6 & Olha eu aí! & Criança olhando para o espelho \\
\hline 7 & É só diversão & Crianças brincando no solário \\
\hline 8 & Já estou chegando & $\begin{array}{l}\text { Criança engatinhando e passando } \\
\text { debaixo de um elástico preso nas } \\
\text { extremidades de dois berços }\end{array}$ \\
\hline 9 & Espelho, espelho meu! & Duas meninas olhando para o espelho \\
\hline
\end{tabular}

Fonte: Elaborado pela autora.

Quadro 2: Títulos das fotos produzidas pelas educadoras do Berçário 2

\begin{tabular}{|l|l|l|}
\hline Foto & \multicolumn{1}{|c|}{ Título } & \multicolumn{1}{c|}{ Descrição } \\
\hline 1 & Momento esconde-esconde & Criança se escondendo de outra criança \\
\hline 2 & Andando de velotrol & Crianças andando de velotrol \\
\hline
\end{tabular}




\begin{tabular}{|l|l|l|}
\hline 3 & A hora do banho & Criança tomando banho na banheira \\
\hline 4 & Deitado no sapo & Criança deitada na almofada temática \\
\hline 5 & Bebeu água? & Criança bebendo água \\
\hline 6 & Deitado na estante & Criança deitada numa prateleira \\
\hline 7 & Cesto de lixo & Cesto de lixo \\
\hline 8 & O portãozinho & Portão baixo de madeira \\
\hline 9 & Hora do almoço & Crianças comendo \\
\hline 10 & Sejam bem-vindos! & Placa pendurada na porta da sala \\
\hline
\end{tabular}

Fonte: Elaborado pela autora.

Dentre as quatro fotos escolhidas para representarem as salas, as educadoras do Berçário 1 separaram as de números 1,2,4 e 7. Já as educadoras do Berçário 2 selecionaram as de número 2,4,5 e 6 . Podemos dizer que as educadoras do Berçário 1 privilegiaram imagens de situações que envolviam sentimentos de amizade e alegria entre os bebês, revelando a concepção de infância feliz que tem orientado muitas práticas pedagógicas nas creches. Já as educadoras do Berçário 2 destacaram as preferências espaciais e conquistas motoras e simbólicas das crianças maiores, sinalizando o salto que as crianças dão com o advento da fala, que costuma aparecer durante o segundo ano de vida.

Quando questionadas a respeito da seleção dos espaços, elas explicaram que os espaços da creche só têm sentido quando vivenciados pelas crianças, acrescentando que, na verdade, foram as crianças que escolheram os lugares para elas fotografarem, como aparecem nos excertos a seguir:

"A gente pega mesmo o momento deles." (Educadora 2)

"É, eu falo assim: as fotos que eles escolheram; eles escolhiam os lugares e a gente fotografava." (Educadora 1)

\section{ANÁLISE DE DADOS}

Percebemos que as experiências de autoria de imagem e de análise e discussão das fotos, por meio da revisitação das cenas produzidas, possibilitaram às educadoras entrarem em contato com as suas percepções acerca dos espaços, bem como das interações e brincadeiras das crianças, desencadeando a reflexão crítica de suas práticas cotidianas. Ficou evidente a intenção das educadoras do Berçário 2 de dar visibilidade aos comportamentos autônomos e criativos das crianças, fruto das intervenções pedagógicas, como verificamos no excerto sobre a foto Deitado no sapo e Bebeu água?: 
"[...] é um momento em que o sapo está no tatame, que a gente utiliza muito, desde a parte da manhã que ele é muito utilizado nas rodinhas e contação de histórias." (Educadora 4)

"Aqui a gente colocou assim: Bebeu água? É o momento em que eles vão até o filtro beber água. Mas, agora, já tem criancinha puxando a mesa e arreganhando o filtro." (Educadora 5)

As educadoras analisaram as fotos considerando as transformações espaciais produzidas pelas próprias crianças.

Procuramos problematizar os elementos presentes na relação entre os arranjos espaciais e as práticas pedagógicas. Na visão das educadoras, a pouca quantidade de brinquedos e mobílias dificulta a organização de ambientes mais interessantes às crianças. Por outro lado, elas compartilham a ideia de que o ambiente para criança pequena requer uma área central vazia para evitar tombos e machucados. Por essa razão, elas explicam que as salas de berçário apresentam o centro sem "obstáculos" para facilitar os deslocamentos dos bebês, engatinhando ou andando de modo vacilante. Esse tipo de arranjo é típico das salas de berçário, e é denominado arranjo espacial aberto (LEGENDRE, 1983), isto é, uma organização espacial cuja estruturação se limita aos contornos do ambiente, por elementos arquitetônicos e não arquitetônicos, como mobília, equipamentos, murais etc.

Retomando as etapas de produção dos dados, a oficina de autoria de imagens revelou o olhar sensível das educadoras para o espaço como elemento relacional, visto que em todas as fotos encontrávamos as crianças interagindo entre si e com os elementos físicos dos ambientes. Igualmente, pudemos perceber, por meio dos comentários sobre as imagens, como os ambientes iam sendo transformados/recriados pelos adultos e pelas crianças, de acordo com as propostas e as rotinas da creche e também com as preferências das crianças, que faziam o movimento de resistência. Assim, as salas mostravam-se mais homogêneas (a sala como um só ambiente) quando eram propostas as atividades pelas educadoras, e mais heterogêneas (com diversos ambientes contidos no ambiente sala) quando as propostas partiam das crianças, notadamente nas brincadeiras.

\section{CONCLUSÃO}


Este trabalho versou sobre a fotografia como recurso metodológico na formação em serviço de educadores de creche, bem como na produção de dados de pesquisa em educação.

A experiência de autoria na produção e análise de imagens possibilitou que as educadoras entrassem em contato com a sua percepção dos espaços, repensando modos de organização espacial e usos dos espaços pelas crianças. As narrativas das imagens e das palavras trouxeram à tona discussões e reflexões férteis sobre os aspectos físicos do ambiente, contribuindo para a construção coletiva de novas/outras significações para aquilo que se encontrava naturalizado e, portanto, invisibilizado.

O estudo demonstrou que a fotografia se constitui num potente recurso na formação de educadores, contribuindo para desenvolver um olhar sensível ao universo infantil e repensar as práticas habituais na creche.

Esperamos que essa experiência contribua para a elaboração de projetos de formação docente que concebem os educadores como coprotagonistas do processo de construção e transformação de saberes e práticas educativas.

\section{REFERÊNCIAS}

BARTHES, R. A câmara clara: nota sobre a fotografia. 9aㅡ ed. Rio de Janeiro: Nova Fronteira, 1984.

BENJAMIN, W. Pequena história da fotografia. In: Magia e técnica, arte e política: ensaios sobre literatura e história da cultura. $8^{\mathrm{a}}$ ed. São Paulo: Brasiliense, 2012.

BOMFIM, J. Arranjos espaciais e ocupação do espaço por crianças de 1-2 e 3-4 anos em creches. Dissertação (Mestrado em Psicologia) - Pós-Graduação em Psicologia. Universidade de São Paulo, Ribeirão Preto, 2002.

Trocas sociais de crianças de 1-2 anos e arranjos espaciais em creches. Tese (Doutorado em Psicologia). Pós-Graduação em Psicologia. Universidade de São Paulo, 2006.

CAMPOS-DE-CARVALHO, M. I. Arranjo espacial e distribuição de crianças de 23 anos pela área de atividades livres em creche. Tese (Doutorado em Psicologia). Pós-Graduação em Psicologia. Universidade de São Paulo. 1990.

FREITAS, M. T. A. Discutindo sentidos da palavra intervenção na pesquisa de abordagem histórico-cultural. In: FREITAS, M. T. A.; RAMOS, B. S. (Orgs.) Fazer 
pesquisa na abordagem histórico-cultural: metodologias em construção. Juiz de Fora, MG: Editora UFJF, 2010. p. 13-24.

GUSMÃO, D. S.; JOBIM e SOUZA, S. A estética da delicadeza nas roças de Minas: sobre a memória e a fotografia como estratégia de pesquisa-intervenção. Psicologia \& Sociedade, vol. 20, Edição Especial, 2008. p. 24-31.

JUSTO, J. S.;VASCONCELOS, M. S. Pensando a fotografia na pesquisa qualitativa em psicologia. Estudos e Pesquisas em Psicologia, Rio de Janeiro, vol.9, no.3, 2009. p. $760-774$.

KOSSOY, B. Fotografia e História. São Paulo: Ateliê Editorial, 2001.

LEGENDRE. A. Approprriation par les enfants de l'environnement architectural. Enfance, Paris, no. 3, 1983. p. 389-395.

Young children's social competences and their use of space in daycare centers. In: SCHEIDEER, B. H.; ATTILI, G. ; NADEL, J; WEISSBERG, R. (Eds.) Social competences in developmental perspective. Dordrecht: Kluwer, 1989. p. 263-276,

Interindividual relationships in groups of young children and susceptibility to an environmental constraint. Environment and behavior. vol.4, no. 31. 1999. p. 463-486.

LIMA, O. A Fotografia é a sua linguagem. Rio de Janeiro: Espaço e Tempo, 1988.

LISBOA, M. M.; PIRES, G. L. Reflexões sobre a imagem e a fotografia:

possibilidades na pesquisa e no ensino de Educação Física. Motrivivência. Ano XXII, n.34, 2010. p. 72-86.

LOPES, A. E. R. de C. Olhares compartilhados: o ato fotográfico como experiência alteraria e dialógica. Tese (Doutorado em Psicologia). Pós-Graduação em Psicologia. PUC-RJ, 2004.

MENEGHINI, R. Relação entre áreas espaciais e interação de crianças pequenas em creche. Dissertação (Mestrado em Psicologia). Pós-Graduação em Psicologia. Universidade de São Paulo, 2000.

MOREIRA, A. R. C. P. Transformações espaciais e interação social entre crianças de dois anos de idade - uma proposta educacional para a creche. Dissertação (Mestrado em Psicologia Social). Pós-Graduação em Psicologia. Universidade Gama Filho. 1992.

OLIVEIRA, M. A.; TAMBORA, E. A. C. Imagens do quotidiano escolar: uma análise das fotografias de práticas escolares publicadas no Relatório Intendencial de 1928, do governo de Augusto Simões Lopes (1924-1298). Revista Lusófona de Educação, 2010, vol.16, no. 16, p. 89-102. 
PRESTES, Z. Quando não é quase a mesma coisa: análise de traduções de Lev Semionovitch Vigotski no Brasil. Campinas/SP: Autores Associados, 2012.

SANTAELLA, L. Os três paradigmas da imagem. In: SAMAIN, E. O fotográfico. São Paulo: Hucitec, 1998. p. 167-178.

SÔNEGO, M. J. F. A fotografia como fonte histórica. Historiae. Rio Grande, vol.1, no. 2, 2010.p. 113-120.

SONTAG, S. Ensaios sobre a fotografia. São Paulo: Companhia das Letras, 2004.

SZUNDY, P. T. C. A construção no jogo e sobre o jogo. Ensino-Aprendizagem de LE e formação reflexiva. Tese (Doutorado em Linguística Aplicada e Estudos da Linguagem) - Pós-Graduação em Linguística. Pontifícia Universidade Católica, 2005.

VIGOTSKI, L. S. Quarta aula: a questão do meio na pedologia. Psicologia USP, São Paulo, vol.21, no.4, 2010. p. 681-701.

VYGOTSKY, L. S. A formação social da mente. Rio de Janeiro: Martins Fontes, 1984. 